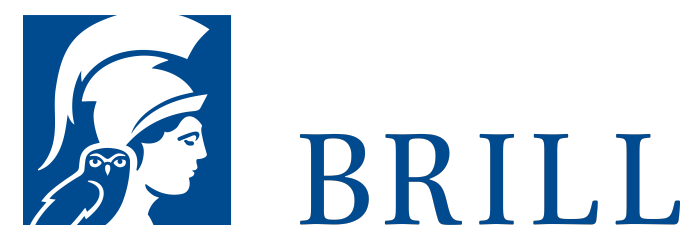

\title{
Ethik der Banken
}

\section{Folgerungen aus der Finanzkrise}

Authors:Jana Koslowski and Peter Koslowski

Die Finanzkrise 2008 war mehr als eine Rezession. Sie war der Zusammenbruch des Bankensystems der Welt, der nur durch die Intervention der Staaten hinausgeschoben werden konnte.Noch weiÃ Ÿ niemand, ob der Zusammenbruch nur verzÃ $\uparrow$ gert oder ob er abgewendet worden ist. Billionen oder gar Trillionen - niemand scheint ihre wahre Dimension zu kennen - von Derivatewetten vagabundieren im Weltbankensystem um den Globus. Ist die Krise die Folge eines Versagens der Banken und ihrer Finanzethik? Die Banken und Finanzintermediãare hielten sich zur ungehemmten

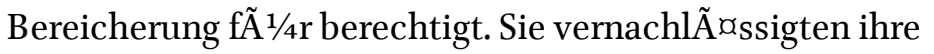
treuhÃønderischen Pflichten gegen $\tilde{A} 1 / 4$ berihren Kunden. Sie fÃ $\llbracket$ rderten die Hyperspekulation und $\tilde{A}^{1}$ /4berzogene inanzwetten. Sie verabschiedeten die Idee, dass die Finanzwirtschaft eine Dienstfunktion hat zugunsten der Maximierung ihrer Einkommen und des Shareholder Value ihrer AktionÃare. Der Vertrauens-und Reputationsverlust der Finanzinstitutionen ist tiefgreifend. Markiert er das Ende des finanzorientierten Kapitalismus? Peter Koslowski zeigt, dass die reinÃ ๆkonomische Ã-konomie der Finanzwirtschaft an ihrem Ende angelangt ist und durch eine ethische $\tilde{A}$-konomie ersetzt werden muss. Er entwickelt eine Ethik der Banken und der FinanzmÃ arkte f $\tilde{A} 1 / 4$ r Kredit, Kapital, Unternehmenskontrolle und Derivate. Die Krise ist auch eine Chance f $\tilde{\mathrm{A}} 1 / 4 \mathrm{r}$ einen Neuanfang, fã $1 / 4$ r eine neue...

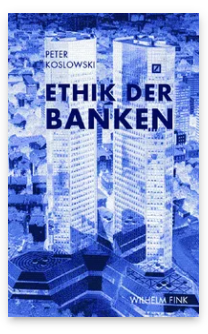

Pages: 274

Seiten

Language:

German

Subjects:

General,

Philosophy

Publisher: Brill |

Fink

E-Book (PDF)

Released online: o2 Sep 2019

ISBN: $978-3^{-}$

8467-4765-0

List price

Paperback

Publication date: 28 Oct 2009

ISBN: $978-3-$ 7705-4765-4

List price

USD. Â $\$ 42.00$ 
For more information see brill.com

Order information: Order online at brill.com +44330 333 0049 | customerservices@brill.com Submission information: brill.com/authors

Titles published by Brill | Fink, Brill | mentis or Brill | Schöningh: +49(o)715413279216| brill@brocom.de 